\title{
Gestionando la pasión
}

Rocío Blay Arráez Universitat Jaume I

La gestión de la información municipal de un ayuntamiento, los temas de campaña en unas elecciones generales y los procesos de comunicación corporativa de los clubes deportivos profesionales, tienen todos ellos un elemento común que hace muy compleja la gestión eficiente de los mismos, el componente emocional y la fuerte implicación personal de los públicos con los que se relacionan. La experiencia vital de cada individuo, muchas veces traducida en actuaciones impulsivas e irreflexivas forma parte de la naturaleza de los temas que en esta sección vamos a tratar y que confieren un grado importante de dificultad a la hora de abordarlos. Por tanto, tener en consideración la pasión que suscitan a la hora de trabajar una metodología para su gestión, pese a su carácter imprevisible, es un reto y una necesidad que estos artículos pretenden estudiar para conocer, prever y poder así, someter a cierto control.

La sección Otras Investigaciones de la revista adComunica en su número 3, pretende dar cabida a aquellos trabajos científicos que no versan sobre la temática específica del monográfico, pero que son de gran interés y actualidad y que por ello, aportan con todo el potencial con el que fueron creados. Y es que estas tres investigaciones que ahora presentamos tienen ese gran potencial que es la contribución no sólo al saber, sino al saber hacer, reivindicando y demostrando cuán necesario es poner en manos de profesionales la gestión de la comunicación para la construcción de una imagen intencional. La contribución de estos artículos, es la posibilidad de dar, rápidamente, transferencia de sus resultados al ámbito profesional mejorando y sobre todo, haciendo más eficientes los procesos comunicativos. 
La orientación de estas investigaciones va enfocada a la proposición de áreas muy precisas de mejora con actuaciones bien definidas, por tanto, son una muestra de cómo la academia aporta a la profesionalización de la comunicación, poniendo de relevancia la necesidad de interactuar activamente con el entorno y prestando un especial interés concretamente a las necesidades del mundo institucional, político y empresarial. Se trata de atender a la denominada tercera misión de la universidad de la que hablaban en mayo del 2006, Suárez y Galán, en unas jornadas sobre empresa y universidad en la Universidad de Zaragoza, donde además de la docencia y la investigación, hay que poner la tilde en el acercamiento del mundo de la empresa/institución a la universidad y viceversa, con todo lo que esto implica.

Prueba de ello lo encontramos en el texto de la profesora de la Universidad de Alicante, Conchi Campillo Alhama sobre La gestión estratégica de la información municipal. Análisis de temas, su tratamiento e irrupción en el Ayuntamiento de Elche (1995-2007). Este artículo parte de la premisa de que contar con el favor del público es vital para que cualquier organización sea legitimada en el desarrollo de su función pública y que para alcanzar este objetivo, juega un papel fundamental el tratamiento informativo sobre determinados asuntos públicos. Pone el acento en cómo en un contexto local sumamente dinámico como es la administración municipal, en la construcción de la imagen organizacional contribuyen diferentes agentes que deben adaptarse a las nuevas circunstancias y exigencias sociales. Para ello, deben establecer procesos de comunicación pública que permitan demostrar a los ciudadanos que constituyen el epicentro de la actuación administrativa. Esta importante tarea actualmente se encuentra en manos de los gabinetes de comunicación municipal que se sitúan, dentro de la organización municipal, junto a los niveles superiores y máximos responsables políticos y administrativos, constituyendo auténticas direcciones de comunicación, pese a que la principal función que asumen son las relaciones informativas. Esta investigación aplicada se centra en el municipio de Elche, donde se estudia la agenda temática durante varias legislaturas, identificando qué temas relacionados con la gestión y la política municipal presentan mayor grado de concurrencia y cuál es su naturaleza e irrupción. Para ello, se emplea la técnica del análisis de contenido de una muestra representativa de periódicos, donde a través de una herramienta metodológica se analizan variables como el tema, el tratamiento y la irrupción. Y concluye, entre otras cosas, que las administraciones públicas deben tomar conciencia de la trascendencia que pueden llegar a alcanzar determinados temas orientados a la ciudadanía, a través de los medios de comunicación local y que esto hace fundamental un análisis como el que presenta.

El segundo trabajo, Análisis de los procesos en la comunicación corporativa de los clubes deportivos profesionales españoles. Estudio exploratorio, de Guillermo Sanahuja de la Universitat Jaume I, comienza poniendo la tilde en cómo en el deporte, sector económico que mueve en torno al 2’5\% del PIB, se sobrepasa 
la originaria función del juego o divertimento para mutar a una fuente de identidad y de consumo. Y es que los propios valores de un club, su historia, cultura y filosofía son capaces de establecer profundos vínculos emocionales y congregar grandes audiencias por encima de los triunfos y éxitos deportivos. Esto justificaría más si cabe, la gestión eficiente de la identidad y la imagen corporativa bajo unos parámetros profesionales. Sin embargo, esta investigación a través de un estudio exploratorio, realiza un estado de la comunicación corporativa y marketing de los clubes profesionales españoles que sirve para denunciar la falta de incorporación de la perspectiva del corporate en el deporte, la descentralización de las comunicaciones, la difusa frontera entre las áreas de comunicación y marketing, además de la ausencia de planificación a largo plazo. A través de trece entrevistas en profundidad a profesionales relevantes de clubes de la Liga de Fútbol Profesional y de la Asociación de Clubes de Baloncesto, confrontado con un panel de expertos, se ha realizado una aproximación a la sensibilidad de éstos, hacia pilares de la comunicación corporativa. Este artículo muestra la inmadurez del sector del deporte, pese a su relevancia, en materia de comunicación frente a otros sectores empresariales, reclamando mayor atención también desde el ámbito académico.

El último estudio, realizado por María Luisa Humanes (Universidad Rey Juan Carlos) y María de los Ángeles Moreno Fernández (Grupo de Estudios Avanzados en Comunicación - GEAC) sobre El efecto agenda sobre los temas de campaña en las elecciones generales de 2008, sitúa no sólo a los medios en el centro de la influencia durante las campañas electorales. En este artículo se realiza una primera revisión sobre las tendencias en los estudios sobre agenda setting, matizando el poder de los medios e introduciendo otras variables como la experiencia, las relaciones personales y el papel de los líderes de opinión, entre otras, para explicar el peso real de cada uno de ellos en el establecimiento de las agendas, sean públicas o políticas. Pero el objetivo principal del trabajo ha sido determinar qué papel juega el consumo de medios en la transferencia de la importancia otorgada a los temas de campaña, y además, considerar las condiciones que pueden afectar al efecto agenda setting. Corroboran finalmente las autoras, la mayor sensibilidad a la influencia del consumo de medios de los temas menos apegados a la experiencia, confirmando que el consumo de información no es el único factor en la atribución de importancia, sino que actúan junto a otros condicionantes relacionados con la experiencia del individuo.

Tres temas en apariencia dispares pero que como al principio se apuntaba, tocan de lleno un componente emocional que condiciona la relación de las organizaciones con sus públicos prioritarios.

\section{Referencia de este artículo}

Blay Arráez, Rocío (2012). Gestionando la pasión. En: adComunica. Revista Científica de Estrategias, Tendencias e Innovación en Comunicación, $\mathrm{n}^{\circ} 3$. Cas- 
tellón: Asociación para el Desarrollo de la Comunicación adComunica, Universidad Complutense de Madrid y Universitat Jaume I, 145-148. DOI: http://dx.doi. org/10.6035/2174-0992.2012.3.9 